Article

\title{
Novel 1,2,3-Triazole Derivatives as Mimics of Steroidal System-Synthesis, Crystal Structures Determination, Hirshfeld Surfaces Analysis and Molecular Docking
}

\author{
Mateusz Daśko ${ }^{1, *} \mathbb{\oplus}$, Anna Dołęga ${ }^{1} \oplus$, Magdalena Siedzielnik ${ }^{1}$, Karol Biernacki ${ }^{2} \mathbb{D}$, Olga Ciupak ${ }^{2}$, \\ Janusz Rachon $^{2}$ and Sebastian Demkowicz ${ }^{2}$ (D) \\ 1 Department of Inorganic Chemistry, Faculty of Chemistry, Gdańsk University of Technology, Narutowicza \\ 11/12, 80-233 Gdańsk, Poland; anna.dolega@pg.edu.pl (A.D.); m.siedzielnik@gmail.com (M.S.) \\ 2 Department of Organic Chemistry, Faculty of Chemistry, Gdańsk University of Technology, Narutowicza \\ 11/12, 80-233 Gdańsk, Poland; karol.biernacki@pg.edu.pl (K.B.); olgaciupak@gmail.com (O.C.); \\ januszrachon@gmail.com (J.R.); sebastian.demkowicz@pg.edu.pl (S.D.) \\ * Correspondence: mateusz.dasko@pg.edu.pl
}

check for updates

Citation: Daśko, M.; Dołęga, A.; Siedzielnik, M.; Biernacki, K.; Ciupak, O.; Rachon, J.; Demkowicz, S. Novel 1,2,3-Triazole Derivatives as Mimics of Steroidal System-Synthesis, Crystal Structures Determination, Hirshfeld Surfaces Analysis and Molecular Docking. Molecules 2021, 26, 4059. https://doi.org/10.3390/ molecules26134059

Academic Editors:

Diego Muñoz-Torrero and

Cristobal De Los Rios

Received: 11 June 2021

Accepted: 1 July 2021

Published: 2 July 2021

Publisher's Note: MDPI stays neutral with regard to jurisdictional claims in published maps and institutional affiliations.

Copyright: (c) 2021 by the authors. Licensee MDPI, Basel, Switzerland. This article is an open access article distributed under the terms and conditions of the Creative Commons Attribution (CC BY) license (https:// creativecommons.org/licenses/by/ $4.0 /)$.

\begin{abstract}
Herein, we present the synthesis and crystal structures determination of five 4-(1-phenyl1H-1,2,3-triazol-4-yl)phenol derivatives containing halogen atoms, $6 \mathbf{a}-\mathbf{e}$, which may be used as an excellent mimic of steroids in the drug development process. Good quality crystals obtained for all of the synthesized compounds allowed the analysis of their molecular structures. Subsequently, the determined crystal structures were used to calculate the Hirshfeld surfaces for each of the synthesized compounds. Furthermore, results of our docking studies indicated that synthesized derivatives are able to bind effectively to the active sites of selected enzymes and receptors involved in the hormone biosynthesis and signaling pathways, analogously to the native steroids.
\end{abstract}

Keywords: triazoles; hormone analogs; drug design; crystal structures; Hirshfeld surface; molecular docking

\section{Introduction}

Triazoles are a class of compounds showing very interesting properties, e.g., hydrogen bond (HB) formation, $\pi-\pi$ stacking interaction, large dipole moments, bioisosteric effects, and therefore, they have been successfully used as scaffolds in the synthesis of antimicrobial, antiviral, and antitumor agents [1]. Importantly, they do not undergo hydrolysis under acidic or basic conditions, and they withstand metabolic degradation, which is desired in the design of new pharmaceuticals. The above advantages indicate that the derivatization of the triazole ring may lead to compounds possessing interesting biological properties. For example, the introduction of two additional phenyl rings with diverse substituents to the 1,2,3-triazole ring should allow the production of 4-(1-phenyl-1H-1,2,3-triazol-4-yl)phenol derivatives demonstrating similarities to some natural compounds, e.g., hormones.

The hormone signaling pathway is a well-established target for the development of hormone-dependent cancer drugs (e.g., breast cancer) [2]. For example, one of the clinically used drugs-Tamoxifen $\mathbf{1}$ (Figure 1) acts as a selective estrogen receptor modulator (SERM). On the other hand, chemotherapeutics, which may influence the hormone formation process, are of high therapeutic importance. The biosynthesis of active steroids (e.g., estradiol (E2) and androstenediol (Adiol)) in cancer tissues mainly depends on three enzymatic pathways: aromatase (AROM), 17 $\beta$-hydroxysteroid dehydrogenase (17 $\beta$-HSD) and steroid sulfatase (STS) [3]. For example, currently used Letrozole 2 and Anastrozole 3 (Figure 1) block the conversion of androgens to estrogens via the inhibition of the AROM complex. In light of recent research indicating that the disorders in sulfation/desulfation processes may be responsible for numerous pathologies [4], the other enzyme implicated in the steroidogenesis process-STS - is becoming a new, interesting molecular target in 
the development of novel and effective hormone-dependent cancer treatment methods. Recently, we have developed a series of tricyclic compounds, featuring the 1,2,3-triazole unit, as potent STS inhibitors [5,6]. In the course of our investigation, we have found that the most active analog, MD77 4 (Figure 1), inhibited the STS enzyme with an $\mathrm{IC}_{50}$ value of $36 \mathrm{nM}$ when evaluated in an enzymatic assay. Our studies indicated that the highest inhibitory activities were exhibited by derivatives containing a fluorine atom at the meta position of the terminal aromatic ring. According to the molecular docking calculations, it was noticed that the fluorine atoms presented in MD77 may interact with the Arg98 residue located in the STS active site. This additional interaction may stabilize the inhibitor-enzyme complex, resulting in improved inhibitory activity [5].
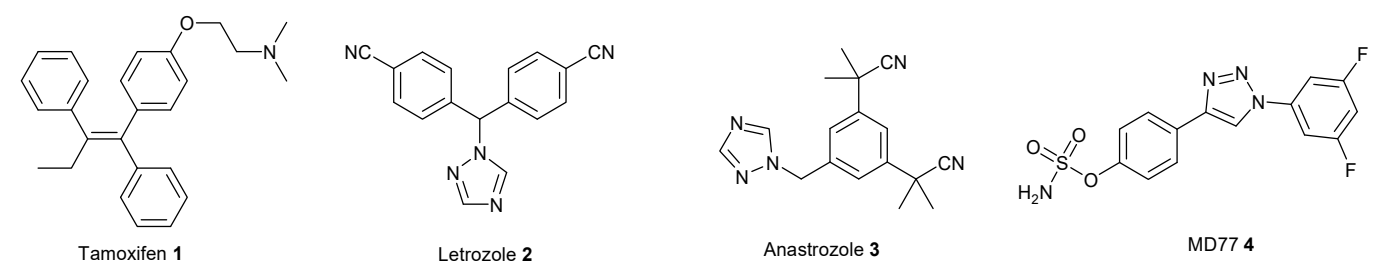

Figure 1. Chemical structures of Tamoxifen 1, Letrozole 2, Anastrozole 3, and MD77 4.

In the present paper, we have reported the crystal structures and Hirshfeld surfaces determination of five 4-(1-phenyl-1H-1,2,3-triazol-4-yl)phenol derivatives. The crystal structures provide insights into the possible conformations and the character of the intermolecular interactions of different derivatives. Additionally, we have described preliminary docking studies indicating effective binding of the synthesized compounds to the active sites of AROM, STS, 17 $\beta$-HSD, and estrogen receptors (ER). The collected data indicate that the reported triazole derivatives could be utilized in the development of novel inhibitors of proteins involved in the hormone biosynthesis and signaling pathways and thus become a perfect starting point in the development of novel anticancer agents.

\section{Results and Discussion}

\subsection{Chemistry}

Three compounds $\mathbf{6 a - c}$ were resynthesized according to the two-step synthetic protocol that we previously described (Scheme 1) [5]. Two novel compounds $6 \mathbf{d}$ and $\mathbf{6 e}$ were synthesized according to the same synthetic pathway using chlorinated aniline derivatives. In the first step, 4-[(trimethylsilyl)ethynyl]phenol 5 was obtained by the Sonogashira reaction between the 4-iodophenol and ethynyltrimethylsilane in the presence of palladium(II) chloride $\left(\mathrm{PdCl}_{2}\right)$, triphenyl phosphine $\left(\mathrm{Ph}_{3} \mathrm{P}\right)$, copper(I) iodide (CuI) and triethylamine $\left(\mathrm{NEt}_{3}\right)$. The Sonogashira coupling is a widely used cross-coupling reaction applied in organic practice to generate carbon-carbon bonds [7]. Next, the appropriate aniline derivatives were transformed into the corresponding azides with tert-butyl nitrite $(t-\mathrm{BuONO})$ and azidotrimethylsilane $\left(\mathrm{TMSN}_{3}\right)$. Then, to the obtained solution, 4-[(trimethylsilyl)ethynyl]phenol 5, a $1 \mathrm{M}$ solution of tetrabutylammonium fluoride (TBAF) in tetrahydrofuran (THF), copper(II) sulfate pentahydrate $\left(\mathrm{CuSO}_{4} \cdot 5 \mathrm{H}_{2} \mathrm{O}\right)$ and a $1 \mathrm{M}$ aqueous solution of sodium ascorbate were added. After a brief work-up of the reaction mixture, the corresponding 4-(1-phenyl-1H-1,2,3-triazol-4-yl)phenol derivatives 6a-e were isolated. Recrystallization in acetonitrile (ACN) (6c-e), methanol (6b), or acetone (6a) allowed to obtain crystals of compounds suitable for $\mathrm{X}$-ray diffraction measurement. 
<smiles>Oc1ccc(I)cc1</smiles><smiles>CC#Cc1ccc(O)cc1</smiles><smiles>[R]c1c([R])c([R])c(N)c([R])c1[R]</smiles><smiles>[R]C1=C([R])C([R])C(N)=C([R])C1[R]</smiles><smiles>[R]c1c([R])c([R])c(-n2cc(-c3ccc(O)cc3)nn2)c([R])c1[R]</smiles>

6a $R_{1}=H, R_{2}=F, R_{3}=H, R_{4}=H, R_{5}=H$ 6b $R_{1}=H, R_{2}=F, R_{3}=H, R_{4}=F, R_{5}=H$ 6c $R_{1}=F, R_{2}=F, R_{3}=F, R_{4}=H, R_{5}=H$ 6d $R_{1}=H, R_{2}=C l, R_{3}=H, R_{4}=H, R_{5}=H$ 6e $\mathrm{R}_{1}=\mathrm{H}, \mathrm{R}_{2}=\mathrm{Cl}, \mathrm{R}_{3}=\mathrm{H}, \mathrm{R}_{4}=\mathrm{Cl}, \mathrm{R}_{5}=\mathrm{H}$

Scheme 1. Synthesis of 4-(1-phenyl-1H-1,2,3-triazol-4-yl)phenol derivatives 6a-e: (a) ethynyltrimethylsilane, $\mathrm{PdCl}_{2}, \mathrm{Ph}_{3} \mathrm{P}$, $\mathrm{CuI}, \mathrm{NEt}_{3}, \mathrm{ACN} ;(b) t$-BuONO$, \mathrm{TMSN}_{3}, \mathrm{ACN}$; (c) TBAF, sodium ascorbate, $\mathrm{CuSO}_{4} \cdot 5 \mathrm{H}_{2} \mathrm{O}$.

\subsection{Crystal Structures and Hirshfeld Surfaces Analysis}

Experimental X-ray crystal structures of $\mathbf{6 a - e}$ may be helpful in the identification of the intermolecular interactions that can arise between the studied molecules and their environment. Good quality crystals obtained for all of the compounds allowed the analysis of their molecular structures (for the parameters of crystallographic data, see Table 3 in the Materials and Methods Section). The asymmetric units contained either one or two molecules of 6a-e; typical examples and numbering schemes are illustrated in Figure 2a-c for compounds $\mathbf{6 a}, \mathbf{6 c}$, and $\mathbf{6 d}$, respectively (the molecular structures of the remaining two compounds can be found as Figures S1 and S2 in ESI). Bond lengths between the atoms, which are collected in Table S1 in ESI, were very similar in all molecules and, in our opinion, did not depend much on the substitution pattern; the mean values of $\mathrm{C}-\mathrm{C}$ bond lengths in the phenol rings were very close when compared between the derivatives ranging from 1.390 to $1.393 \AA$. The mean values of $\mathrm{C}-\mathrm{C}$ bonds in the halogenated rings were invariably shorter and varied from $1.380 \AA$ to $1.387 \AA$ (Table S1, ESI).

a)

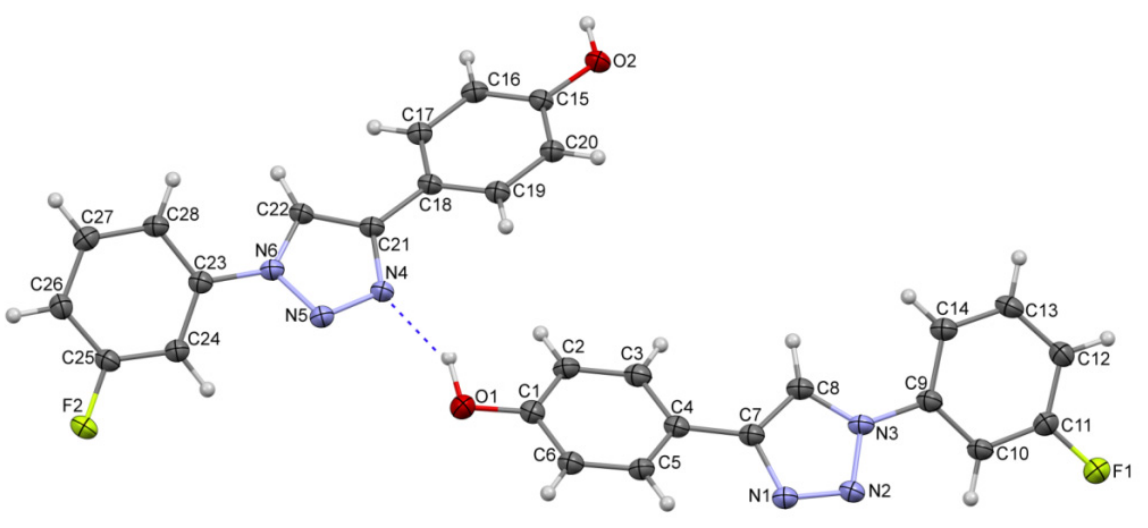

b)

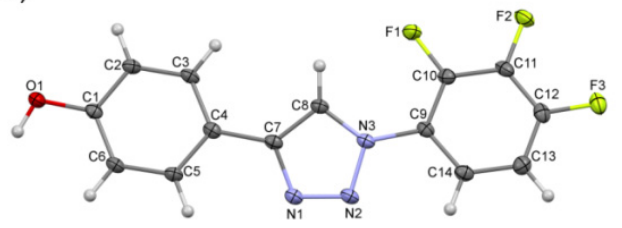

c)

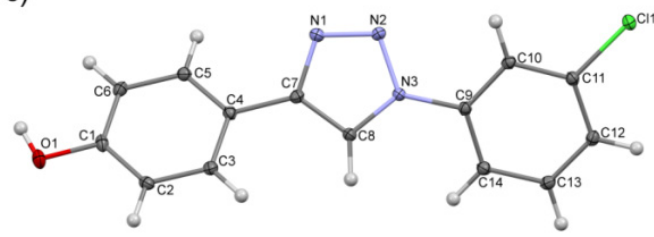

Figure 2. Molecular structures of (a) 6a; (b) 6c; (c) 6d. Thermal ellipsoids at 50\%. 
The substituted phenyl rings in $\mathbf{6 a - e}$ can adopt different mutual orientations. The torsion angles between the six-membered rings varied from $0.90^{\circ}$ in $6 \mathrm{e}$ to $50.41^{\circ}$ in $6 \mathbf{a}$. It can be observed that the same molecule can exhibit different torsion angles within the same crystal-as in $\mathbf{6 a}$ and $\mathbf{6 e}$ (Table S1, ESI). Moreover, the mutual rotation of the rings may introduce a helical type of chirality, and we do observe two helical enantiomers of $\mathbf{6 a}$ in crystals. In the examples presented in Figure 2 for $\mathbf{6 a} \mathbf{6} \mathbf{6 c}$, and $\mathbf{6 d}$ compounds, atoms of halogens are asymmetrically attached to the phenyl ring (with regard to triazole substitution), which leads to two possibilities of their orientation with regard to the triazole ring. The mono-substituted rings in $\mathbf{6 a}$ and $\mathbf{6} \mathbf{d}$ realize common conformation with the torsions N2-N3-C11-F1/Cl1 $17.46^{\circ} / 20.32^{\circ}$, respectively, whereas in $6 \mathrm{c}$, the additional intramolecular contact between $\mathrm{H} 8$ and F1 (2.415 $\mathrm{A})$ may impose the opposite arrangement with the torsion N2-N3-C11-F2 equal to $154.62^{\circ}$ (Figure 2 ).

Geometrical parameters of intermolecular interactions characteristic for compounds 6a-e are collected in Table S2 (ESI) and the crystal packings are illustrated in Figure $3 \mathrm{a}, \mathrm{b}$ and in Figures S3-S5 (ESI). The most typical interactions between the molecules included classical hydrogen bonds, which usually formed between the phenol group of one molecule and N1/N2 atoms of the triazole ring of the adjacent molecule (Figure 3a). The only exception to this pattern was compound $\mathbf{6 d - i n}$ the crystal packing of $\mathbf{6} \mathbf{d}$ the $\mathrm{OH}$... O supported chains are observed, and such change probably allowed the formation of additional halogen bonding interaction, as indicated in Figure $3 b$ and Table S2 (ESI). The intermolecular interactions of derivatives containing fluorine atoms always include $\mathrm{CH}$. . F contacts; the shortest one, which is observed in $\mathbf{6 c}$, exhibits the donor-acceptor distance below $3 \AA$, implicating quite strong interaction. As shown in Figure $3 a$, the intermolecular forces are usually strongest in the approximate plane of each molecule, which leads to the formation of hydrogen-bonded 2-D arrangements.

Based on the determined crystal structures of compounds $\mathbf{6 a - e}$, the Hirshfeld surfaces (HSs) were mapped with a $\mathrm{d}_{\text {norm }}$ function, which are illustrated in Figure 4 with fingerprint decomposition. The calculated HSs of molecules $6 \mathbf{6 a}-\mathbf{e}$ indicated the presence of strong $\mathrm{O}-\mathrm{H} \cdot \cdots \mathrm{N}$ contacts between molecules, which are represented by the red spots shown in Figure 4. Moreover, the blue regions correspond to weak interactions, such as $\mathrm{C}-\mathrm{H} \cdots \mathrm{H}$ contacts. According to the decomposed fingerprint plots of compounds $\mathbf{6 a}-\mathbf{e}$, it was noticed that the most important interactions between molecules are van der Waals forces. The diagram of 6 a shows that the $\mathrm{C} \cdots \mathrm{H}(33.4 \%)$ bonds are major factors in the crystal packing with hydrophobic $\mathrm{H} \cdots \mathrm{H}(24.7 \%)$ interactions, which are the next highest contribution. The decomposed fingerprint plots confirmed that with the increase in the number of fluorine atoms in the molecule of $\mathbf{6 b}$ and $\mathbf{6 c}$, the F. . X interactions become very important $(28.4 \%$ in $\mathbf{6 b}$ ) or even prevailing ( $38.7 \%$ in $\mathbf{6 c}$ ) intermolecular forces. Based on the fingerprint plots of $6 \mathrm{~d}$, it was detected that the major factors in the crystal packing are hydrophobic $\mathrm{H} \cdots \mathrm{H}$ $(22.2 \%)$ and $\mathrm{C} \cdot \mathrm{H}(34.7 \%)$ bonds. As in $6 \mathrm{a}-6 \mathrm{c}$ series, with the increase in the number of halogen atoms, their intermolecular interactions grow in strength and become an important structure-building factor. Accordingly, in 6e, Cl ..X X (30.1\%) becomes comparable with the hydrophobic $\mathrm{H} \cdots \mathrm{H}$ plus $\mathrm{C} \cdot \mathrm{H}$ (35.1\%). 
a)
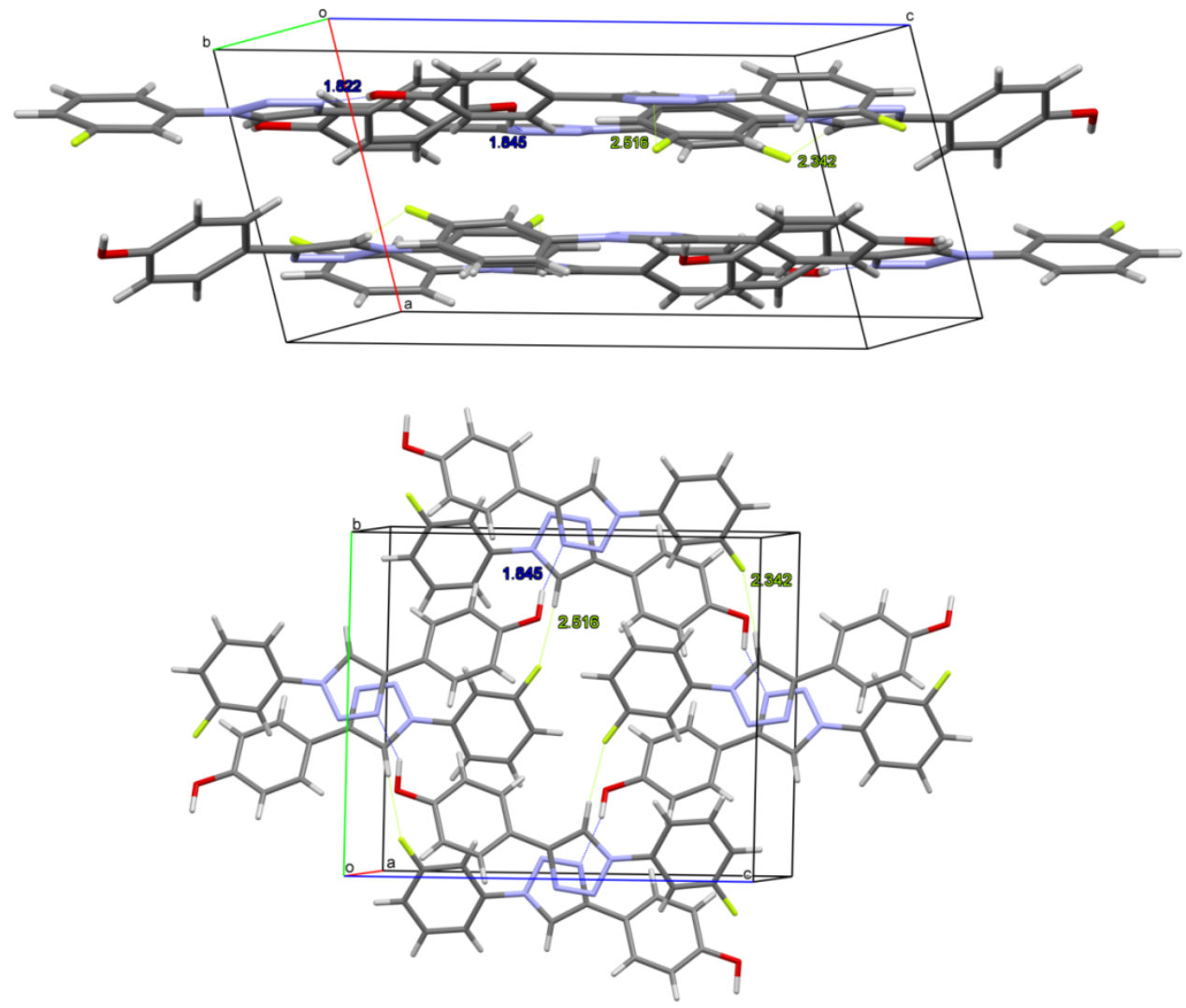

b)

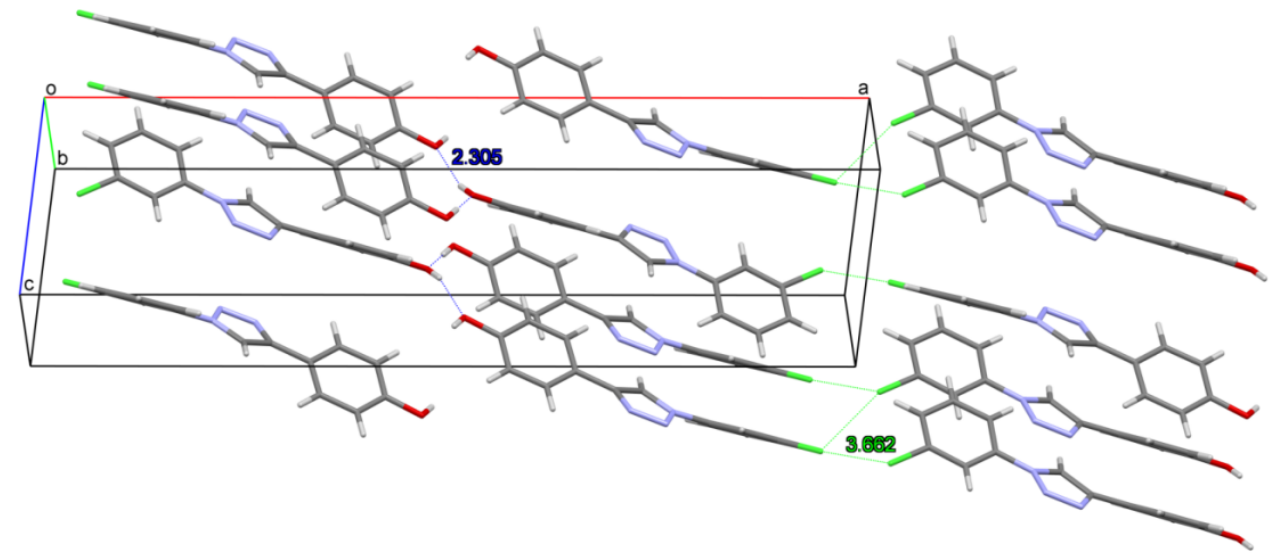

Figure 3. Crystal packings and intermolecular interactions in (a) 6a; (b) 6d. 

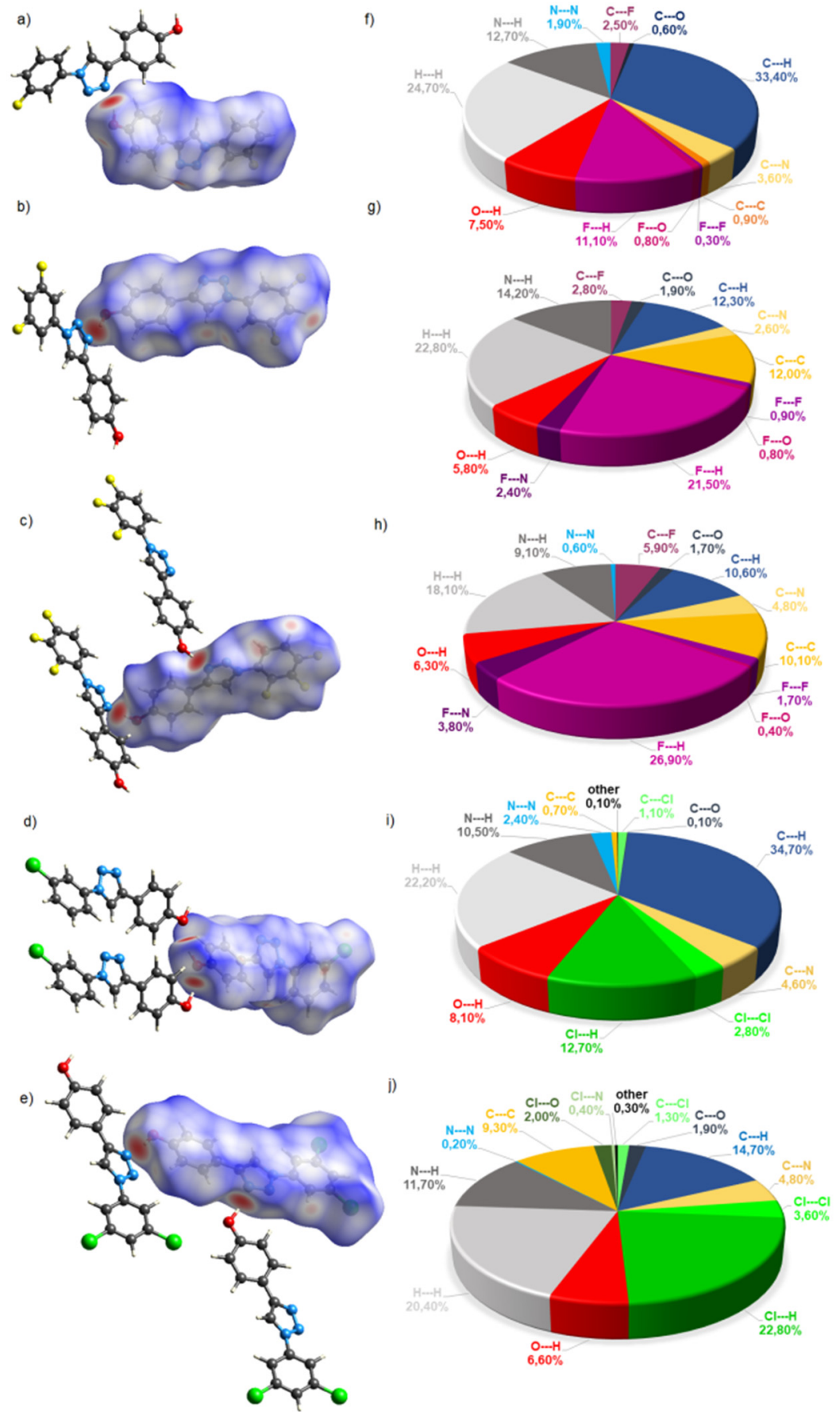

Figure 4. Hirshfeld surfaces of (a) 6a, (b) 6b, (c) 6c, (d) 6d, (e) 6e. Red color: normalized contact distances for $6 \mathbf{a}-\mathbf{e}$ : $d_{\text {norm }}$ shorter than the sum of van der Waals radii (for $6 \mathbf{a}: d_{\text {norm }}=-0.6166 ; 6 \mathbf{b}$ : $\left.d_{\text {norm }}=-0.5728 ; 6 c: d_{\text {norm }}=-0.5901 ; 6 \mathrm{~d}: d_{\text {norm }}=-0.3820 ; 6 e: d_{\text {norm }}=-0.6177\right)$, white color: van der Waals contacts (for $6 \mathbf{a}: d_{\text {norm }}=0.4140 ; \mathbf{6 b}: d_{\text {norm }}=0.3931 ; 6 \mathbf{c}: d_{\text {norm }}=0.3738 ; 6 \mathbf{d}: d_{\text {norm }}=0.3266$; 6e: $\left.d_{\text {norm }}=0.4040\right)$, blue color: normalized contact distances exceeding the sum of van der Waals radii (for $6 \mathbf{a}: d_{\text {norm }}=1.3683 ; 6 \mathbf{b}$ : $d_{\text {norm }}=1.2271 ; 6 \mathbf{c}$ : $d_{\text {norm }}=1.1824 ; 6 d$ : $d_{\text {norm }}=1.0046 ; 6 \mathbf{e}: d_{\text {norm }}=$ 1.1712); (f-j), Hirshfeld surface fingerprint decompositions showing main types of interactions for compounds 6a-e.

\subsection{Computational Studies}

\subsubsection{The Lipinski's Rule of Five Calculations}

The free access web tool SwissADME server (Swiss Institute of Bioinformatics, Lausanne, Switzerland) was used to predict drug-like physicochemical (PC) properties of 
compounds 6a-e based on Lipinski's Rule of Five (molecular weight less than 500, log $\mathrm{P}$ or coefficient partition between -5 and 5 , less than five HB donors, and less than ten HB acceptors) [8]. Our calculations indicated that compounds $\mathbf{6 a - e}$ demonstrate desired drug-like PC features (the collected data are summarized in Table 1).

Table 1. Computed drug-like PC properties of compounds 6a-e based on Lipinski's Rule of Five.

\begin{tabular}{cccccccccc}
\hline No. & $\mathbf{R}_{\mathbf{1}}$ & $\mathbf{R}_{\mathbf{2}}$ & $\mathbf{R}_{\mathbf{3}}$ & $\mathbf{R}_{\mathbf{4}}$ & $\mathbf{R}_{\mathbf{5}}$ & $\begin{array}{c}\text { Molecular } \\
\text { Weight (g/mol) }\end{array}$ & Log P & $\begin{array}{c}\text { Number of HB } \\
\text { Donors }\end{array}$ & $\begin{array}{c}\text { Number of HB } \\
\text { Acceptors }\end{array}$ \\
\hline $\mathbf{6 a}$ & $\mathrm{H}$ & $\mathrm{F}$ & $\mathrm{H}$ & $\mathrm{H}$ & $\mathrm{H}$ & 255.25 & 2.67 & 1 & 4 \\
$\mathbf{6 b}$ & $\mathrm{H}$ & $\mathrm{F}$ & $\mathrm{H}$ & $\mathrm{F}$ & $\mathrm{H}$ & 273.24 & 2.97 & 5 \\
$\mathbf{6 c}$ & $\mathrm{F}$ & $\mathrm{F}$ & $\mathrm{F}$ & $\mathrm{H}$ & $\mathrm{H}$ & 291.23 & 3.22 & 1 & 6 \\
$\mathbf{6 d}$ & $\mathrm{H}$ & $\mathrm{Cl}$ & $\mathrm{H}$ & $\mathrm{H}$ & $\mathrm{H}$ & 271.70 & 2.90 & 1 & 3 \\
$\mathbf{6 e}$ & $\mathrm{H}$ & $\mathrm{Cl}$ & $\mathrm{H}$ & $\mathrm{Cl}$ & $\mathrm{H}$ & 306.15 & 3.42 & 1 & 3 \\
\hline
\end{tabular}

\subsubsection{Molecular Docking}

Our previous research indicated that some of the sulfamoylated derivatives of compounds 6a-e (e.g., MD77 4) demonstrated very high STS inhibitory properties, and therefore, they might be recognized as drug candidates in the treatment of hormone-dependent types of cancers. In the present studies, we performed molecular docking calculations to the active sites of several molecular targets (AROM, STS, 17 $\beta$-HSD1, ER $\alpha$, and ER $\beta$ ) for compounds 6a-e using AutoDock Vina 1.1.2 software (Molecular Graphics Laboratory, The Scripps Research Institute, LaJolla, CA, USA). The obtained data indicated that the 4-(1-phenyl-1H-1,2,3-triazol-4-yl)phenol core may be useful in the development of novel inhibitors of the abovementioned proteins. The summarized results of docking calculations are presented in Table 2. Subsequently, the visualizations of the examples of docked compounds using VMD 1.9 software (University of Illinois at Urbana-Champaign, Urbana, IL, USA) and detailed identification of plausible interactions using BIOVIA software (Dassault Systémes, Discovery Studio Visualiser, San Diego, CA, USA) were performed.

Table 2. Binding free energies of compounds 6a-e and references (androstenedione, estrone sulfate (E1S), estrone (E1) and, estradiol (E2)) to the AROM, STS, 17 $\beta$-HSD1, ER $\alpha$, and ER $\beta$.

\begin{tabular}{|c|c|c|c|c|c|c|c|c|c|c|}
\hline \multirow{2}{*}{ No. } & \multirow{2}{*}{$\mathbf{R}_{1}$} & \multirow{2}{*}{$\mathbf{R}_{2}$} & \multirow{2}{*}{$\mathbf{R}_{3}$} & \multirow{2}{*}{$\mathbf{R}_{4}$} & \multirow{2}{*}{$\mathbf{R}_{5}$} & \multicolumn{5}{|c|}{ Binding Free Energy $\left(\mathrm{kcal} \mathrm{mol}^{-1}\right)$} \\
\hline & & & & & & AROM & STS & 17 $\beta$-HSD1 & $\mathrm{ER} \alpha$ & $E R \beta$ \\
\hline $6 a$ & $\mathrm{H}$ & $\mathrm{F}$ & $\mathrm{H}$ & $\mathrm{H}$ & $\mathrm{H}$ & -8.3 & $-8.1 /-7.1 *$ & -7.9 & -8.8 & -8.5 \\
\hline $6 b$ & $\mathrm{H}$ & $\mathrm{F}$ & $\mathrm{H}$ & $\mathrm{F}$ & $\mathrm{H}$ & -7.9 & $-8.3 /-6.6^{*}$ & -8.2 & -8.5 & -8.7 \\
\hline $6 c$ & $\mathrm{~F}$ & $\mathrm{~F}$ & $\mathrm{~F}$ & $\mathrm{H}$ & $\mathrm{H}$ & -7.7 & $-8.3 /-7.9 *$ & -8.5 & -8.5 & -8.9 \\
\hline $6 d$ & $\mathrm{H}$ & $\mathrm{Cl}$ & $\mathrm{H}$ & $\mathrm{H}$ & $\mathrm{H}$ & -7.5 & $-8.1 /-6.9 *$ & -8.0 & -8.2 & -8.5 \\
\hline $6 e$ & $\mathrm{H}$ & $\mathrm{Cl}$ & $\mathrm{H}$ & $\mathrm{Cl}$ & $\mathrm{H}$ & -5.5 & $-8.3 /-6.9 *$ & -8.4 & -7.9 & -7.6 \\
\hline Androstenedione & - & - & - & - & - & -12.4 & - & - & - & - \\
\hline E1S & - & - & - & - & - & - & -6.3 & - & - & - \\
\hline E1 & - & - & - & - & - & - & -8.9 & -8.9 & - & - \\
\hline E2 & - & - & - & - & - & - & - & - & -10.7 & -11.1 \\
\hline
\end{tabular}

* unsulfated/sulfated forms.

\section{AROM}

The calculated binding free energies of compounds $\mathbf{6 a}-\mathbf{d}$ to AROM were comparable and in the range of -7.5 to $-8.3 \mathrm{kcal} \mathrm{mol}^{-1}$ (Table 2). Only the binding free energy for compound 6e was significantly higher $\left(-5.5 \mathrm{kcal} \mathrm{mol}^{-1}\right)$. In general, the binding free energies calculated for fluorinated derivatives were slightly better than their chlorinated analogs. However, all of the calculated values were less favorable than the binding free energy of androstenedione $\left(-12.4 \mathrm{kcal} \mathrm{mol}^{-1}\right)$, indicating a slightly worse match to the enzyme's active site than the natural substrate. Analysis of docking modes of compounds 
6a-e indicated that triazole rings are close to the heme $\mathrm{Fe}^{2+}$ (e.g., $4.14 \AA$ for compound 6b. Figure 5) analogously as a methyl group of androstenedione (3.94 $\AA$ ). Furthermore, the halogenated rings of compounds $\mathbf{6 a}-\mathbf{e}$ occupied the same region of the enzyme's binding site like a five-membered ring of androstenedione. For example, the distance between one of the fluorine atoms of compound $\mathbf{6 b}$ and Asp309 was $2.36 \AA$ (in the case of androstenedione, the distance between the carbonyl group and Asp309 was $3.02 \AA$ ). A more detailed list of the plausible interactions between compounds $6 \mathbf{a}-\mathbf{e}$ and the AROM enzyme was obtained using BIOVIA and presented in Table S3 (ESI).

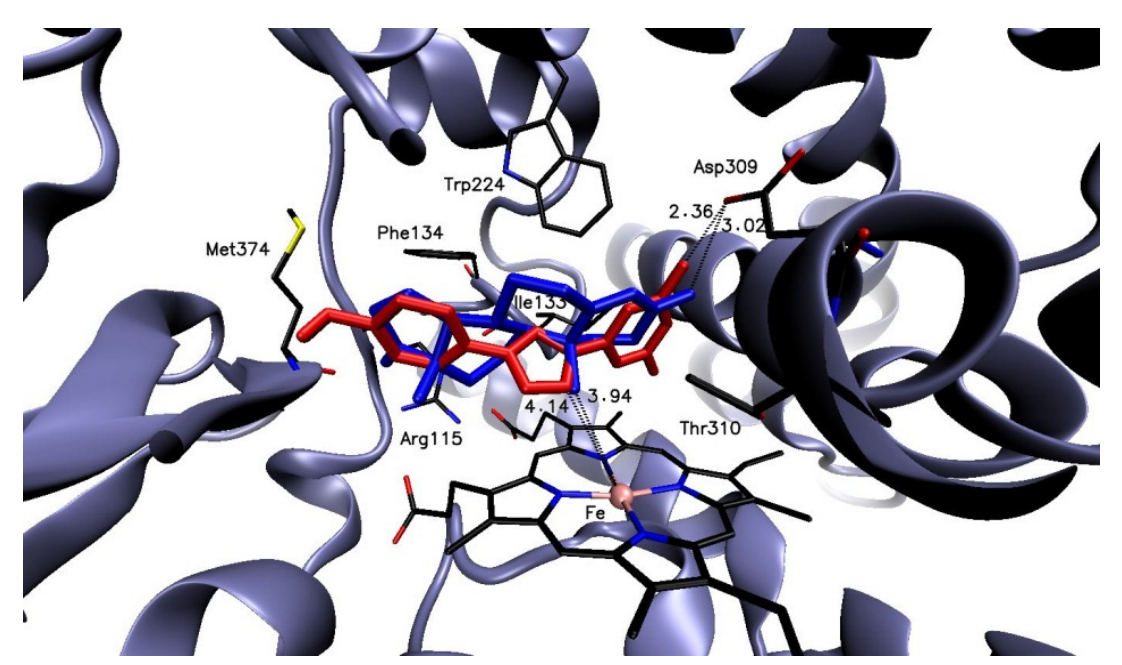

Figure 5. The binding mode of compound $\mathbf{6 b}$ (red) and androstenedione (blue) in the AROM active site.

\section{STS}

Initially, the docking calculations to the STS protein were performed for compounds $\mathbf{6 a}-\mathbf{e}$ and E1 (used as a reference). The calculated binding free energies of compounds $\mathbf{6 a - e}$ were in the range of -8.1 to $-8.3 \mathrm{kcal} \mathrm{mol}^{-1}$ (Table 2) and were slightly less favorable than the binding free energy value of E1 $\left(-8.9 \mathrm{kcal} \mathrm{mol}^{-1}\right)$. There were no significant differences between binding free energy values for fluorinated and chlorinated analogs. Analysis of docking modes of compounds $\mathbf{6 a}-\mathbf{e}$ and E1 indicated their similar binding manner to the STS active site. As it is presented in Figure $6 \mathrm{~A}$ for representative 6 e derivative, we found that the $-\mathrm{OH}$ groups of compound $6 \mathrm{e}$ and $\mathrm{E} 1$ are in a short distance to the catalytic amino acid residue fGly75 ( 3.13 and $2.72 \AA$, respectively) coordinated to the $\mathrm{Ca}^{2+}$ ion. Furthermore, we detected that the halogen atoms of compounds $\mathbf{6 a}-\mathbf{e}$ occupied the same region of the STS active site as the carbonyl group of E1, indicating the presence of possible interactions with Arg98.

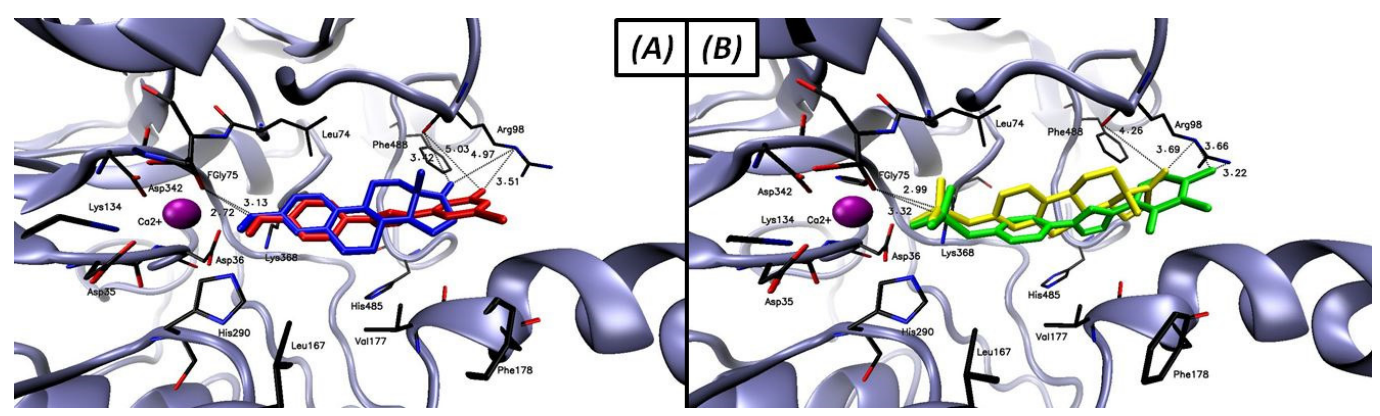

Figure 6. The binding mode of compound: (A) 6e (red) and E1 (blue); (B) sulfate of 6c (green) and E1S (yellow) in the STS active site. 
However, taking into consideration the mechanism of the enzymatic reaction catalyzed by the STS, we prepared and docked a set of sulfated derivatives of compounds $6 a-e$. Their calculated binding free energies were in the range of -6.6 to $-7.8 \mathrm{kcal} \mathrm{mol}^{-1}$ (Table 2) and were more favorable than the binding free energy value of E1S $\left(-6.3 \mathrm{kcal} \mathrm{mol}^{-1}\right)$, used as a reference. Figure $6 \mathrm{~B}$ shows the structure of the sulfated derivative of $\mathbf{6 c}$ and E1S docked into the active site of STS. We found that the sulfate groups of the sulfated derivative of 6c and E1S were located very close to the fGly75 residue (3.32 and $2.99 \AA$, respectively). Analogously, as it was detected in the case of phenolic derivatives 6a-e, the halogen atoms of their sulfated derivatives were also in close distances to the Arg98 residue indicating the presence of interactions, which may stabilize the enzyme-ligand complexes.

Importantly, more favorable binding free energy values were calculated for sulfates of compounds 6a-e in comparison with E1S, indicating better binding of ligands based on the 4-(1-phenyl-1H-1,2,3-triazol-4-yl)phenol core before catalysis than the natural substrate. On the other hand, less favorable binding free energies were calculated for phenolic derivatives $\mathbf{6 a}-\mathbf{e}$ in comparison with E1, indicating easier dissociation of the compounds after catalysis. Both of the mentioned observations suggest that the enzymatic reaction for compounds containing 4-(1-phenyl-1H-1,2,3-triazol-4-yl)phenol core may be more effective in comparison with the hydrolysis of E1S to E1. A more detailed list of the plausible interactions between compounds $\mathbf{6 a}-\mathbf{e}$ in their phenolic and sulfate forms and STS enzyme was obtained using BIOVIA and presented in Table S4 (ESI).

\section{$17 \beta-H S D 1$}

The calculated binding free energies of compounds $6 \mathbf{a}-\mathbf{e}$ to $17 \beta-\mathrm{HSD} 1$ were comparable (in the range of -7.9 to $-8.5 \mathrm{kcal} \mathrm{mol}^{-1}$ Table 2) and slightly higher than the binding free energy value of $\mathrm{E} 1\left(-8.9 \mathrm{kcal} \mathrm{mol}^{-1}\right)$. Fluorinated and chlorinated derivatives both demonstrated similar binding free energy values. Compounds $\mathbf{6 a}-\mathbf{e}$ docked to the $17 \beta$-HSD1's active site analogously as it was determined for E1 (the halogenated rings of compound 6a-e occupied the same region as a five-membered ring of E1). As it is presented for compound $\mathbf{6 c}$ (Figure 7), we found that the fluorine atoms present in the meta and para positions of the terminal aromatic ring were in close distances to the Ser142 and Tyr155 amino acid residues (the distances of meta-F-HO-Ser142, meta-F-HO-Tyr155 and para-FHO-Tyr155 were 3.13, 2.95 and $3.31 \AA$, respectively). In comparison, the distances between the carbonyl group of the E1 and Ser142 and Tyr155 were 5.29 and $4.45 \AA$, respectively. The -OH groups of compound $\mathbf{6 c}$ and E1 occupied strictly the same region of the enzyme's active site and were in short distances to the His221 and Gly282 amino acid residues (2.97 and $3.06 \AA$ for $\mathbf{6 c}$ ). All plausible interactions between compounds $\mathbf{6 a}-\mathbf{e}$ and the $17 \beta-\mathrm{HSD} 1$ enzyme were obtained using BIOVIA and collected in Table S5 (ESI).

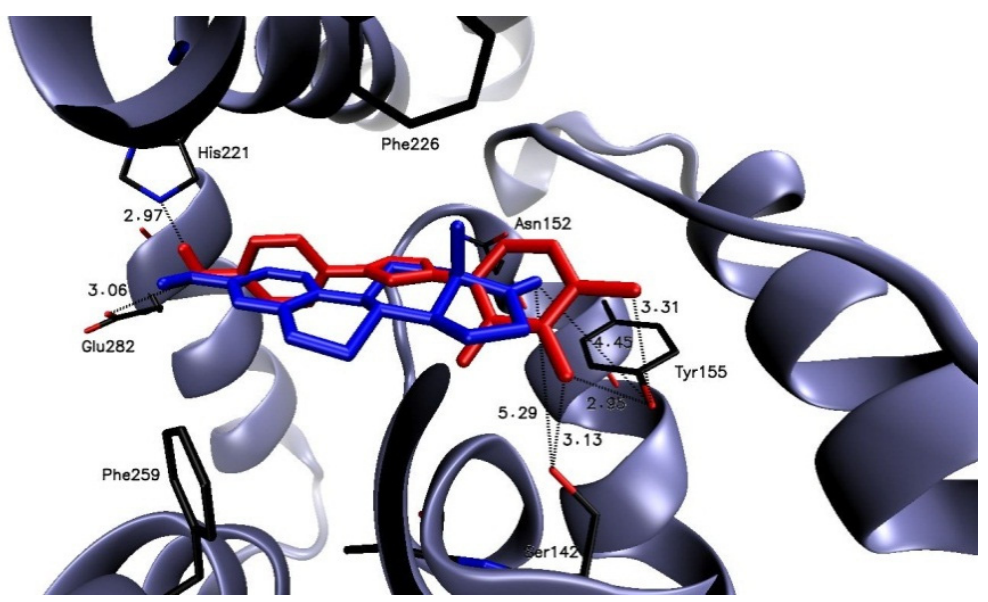

Figure 7. The binding mode of compound $6 \mathrm{c}$ (red) and E1 (blue) in the 17 $\beta$-HSD1 active site. 


\section{$\mathrm{ER} \alpha$ and $\mathrm{ER} \beta$}

The calculated binding free energies of compounds $6 \mathbf{a}-\mathbf{e}$ to $E R \alpha$ and $E R \beta$ were similar (in the range of -7.9 to $-8.8 \mathrm{kcal} \mathrm{mol}^{-1}$ and -7.6 to $-8.9 \mathrm{kcal} \mathrm{mol}^{-1}$, respectively, Table 2), suggesting their effective association to the ER $\alpha$ and ER $\beta$ binding sites (the binding free energy values of E2 were -10.7 and $-11.1 \mathrm{kcal} \mathrm{mol}^{-1}$, respectively). In both cases, the binding free energy values calculated for fluorinated derivatives were slightly better than their chlorinated analogs; however, in our opinion, the differences are too low to indicate them as significant. Compounds $6 \mathbf{a}-\mathbf{e}$ docked to the ER $\alpha$ 's and ER $\beta^{\prime}$ s binding sites in a similar manner as reported for E2. As it is presented in Figure 8A, we found that the -OH groups of compound $\mathbf{6 c}$ and E2 were in short distances to the Glu353 and Arg394 amino acid residues of $\mathrm{ER} \alpha$ ( 2.70 and $2.80 \AA$ for $\mathbf{6 c}$, respectively; 2.92 and $3.21 \AA$ for E2, respectively). On the opposite side of the binding region of $E R \alpha$, we detected that the halogens atoms of compounds $\mathbf{6 a - e}$ occupied the same region as the -OH group of E2, indicating the presence of interactions with His524. For example, the distance between the para-substituted fluorine atom of $6 \mathrm{c}$ and the nitrogen atom of His524 was $2.72 \AA$ (analogously, the distance between the -OH group of E2 and His524 was $2.93 \AA$ ). In case of docking to ER $\beta$ 's binding site (Figure $8 \mathrm{~B}$ ), we detected that -OH groups of compounds 6a-e were in short distances to the Glu305 and Arg346 amino acid residues analogously to E2 (for example, 2.90 and $3.63 \AA$ for $6 \mathbf{c}$, respectively; 2.93 and $2.91 \AA$ for E2, respectively). Furthermore, halogen atoms of compounds $6 \mathbf{a}-\mathbf{e}$ occupied the same region of ER $\beta$ like $-\mathrm{OH}$ group of E2. The para-substituted fluorine atom of compound $\mathbf{6 c}$ was at a distance of $3.05 \AA$ to the nitrogen atom of His475 (for comparison, the distance between the $-\mathrm{OH}$ group of E2 and His475 was $3.17 \AA$ ). Tables S6 and S7 (ESI) summarizes all of the plausible interactions between compounds 6a-e and both ERs detected using BIOVIA.

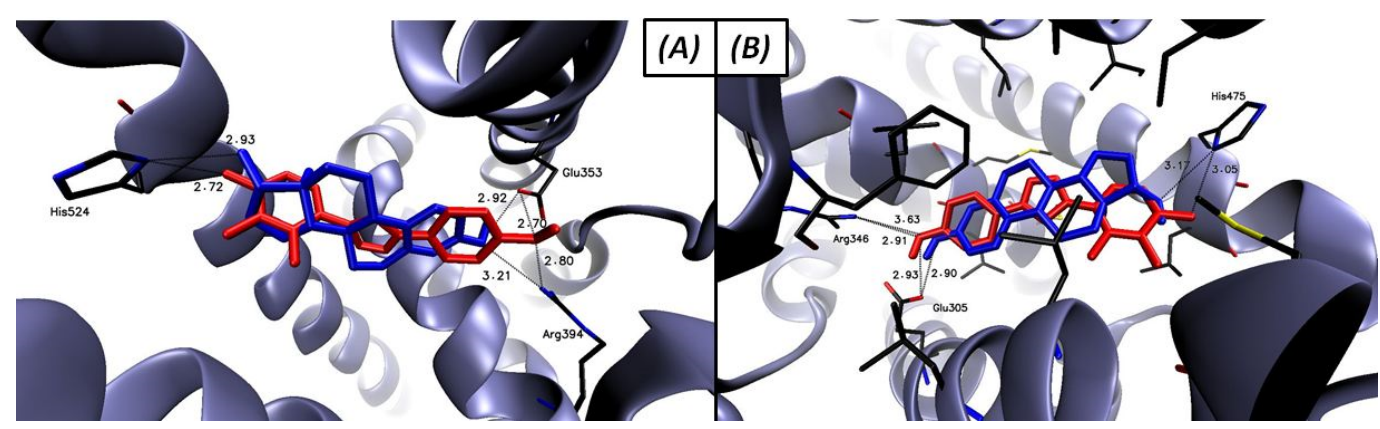

Figure 8. The binding modes of compound $6 \mathrm{c}$ (red) and E2 (blue) in the ER $\alpha(\mathbf{A})$ and ER $\beta$ (B) binding sites.

\section{Materials and Methods}

\subsection{Synthesis}

4-iodophenol, trimethylsilylacetylene, $\mathrm{PdCl}_{2}, \mathrm{PPh}_{3}, \mathrm{CuI}, \mathrm{NEt}_{3}, 1 \mathrm{M}$ solution of TBAF in $\mathrm{THF}$, sodium ascorbate, $\mathrm{CuSO}_{4} \cdot 5 \mathrm{H}_{2} \mathrm{O}, t$-BuONO, $\mathrm{TMSN}_{3}$, all of the used aniline derivatives, and solvents are commercially available from Merck (Merck KGaA, Darmstadt, Germany). Solvents were dried and distilled using standard procedures. Melting points (uncorrected) were determined with a Stuart Scientific SMP30 apparatus (Stuart, Stone, UK). NMR spectra were recorded on a Bruker Avance III HD $400 \mathrm{MHz}$ spectrometer (Bruker, Billerica, MA, USA). Chemical shifts are reported in ppm relative to the residue solvent peak (DMSO-d 2.49 ppm for ${ }^{1} \mathrm{H}, 39.5$ ppm for ${ }^{13} \mathrm{C}$ ). Coupling constants are given in Hertz. IR spectra were recorded on a Nicolet 8700 spectrometer (Thermo Fisher, Waltham, MA, USA). Mass spectra were recorded on an Agilent 6540 Accurate Mass Q-TOF LC/MS System (Agilent, Santa Clara, CA, USA). Column chromatography was performed using silica gel 60 (230-400 mesh, Merck KGaA, Darmstadt, Germany). Elemental analysis was performed using a CHNS-Carlo Erba EA-1108. Preparative thin-layer chromatography was performed with Polygram SIL G/UV 254 silica gel (Macherey-Nagel GmbH and Co. 
KG, Düren, Germany). The detailed procedure for the synthesis of compounds $\mathbf{6 a}-\mathbf{e}$ was previously described (with the characterization of compounds 6a-c) [5]. Recrystallization in acetonitrile (ACN) (6c-e), methanol (6b), or acetone (6a) allowed to obtain crystals of compounds suitable for X-ray diffraction measurement.

4-[1-(3-chlorophenyl)-1H-1,2,3-triazol-4-yl]-phenol 6d. Yield 70\%; mp 208-209 ${ }^{\circ} \mathrm{C}$; $v_{\max }(\mathrm{KBr}) / \mathrm{cm}^{-1} 3458,1616,1591,1466,1222,1175,1040,839,681 ;{ }^{1} \mathrm{H}$ NMR $\delta_{\mathrm{H}}(400 \mathrm{MHz}$, DMSO) $9.70(1 \mathrm{H}, \mathrm{s}, \mathrm{OH}), 9.19(1 \mathrm{H}, \mathrm{s}, \mathrm{CH}), 8.07(1 \mathrm{H}, \mathrm{t}, J 2.0 \mathrm{~Hz}, \mathrm{Ar}-\mathrm{H}), 7.98-7.93(1 \mathrm{H}, \mathrm{m}$, Ar-H), $7.75(2 \mathrm{H}, \mathrm{d}, J 8.7 \mathrm{~Hz}, \mathrm{Ar}-\mathrm{H}), 7.66(1 \mathrm{H}, \mathrm{t}, J$ J $8.1 \mathrm{~Hz}, \mathrm{Ar}-\mathrm{H}), 7.60-7.55(1 \mathrm{H}, \mathrm{m}, \mathrm{Ar}-\mathrm{H})$, $6.89(2 \mathrm{H}, \mathrm{d}, J 8.7 \mathrm{~Hz}, \mathrm{Ar}-\mathrm{H}) ;{ }^{13} \mathrm{C}$ NMR $\delta_{\mathrm{C}}(101 \mathrm{MHz}, \mathrm{DMSO}) 158.2,148.3,138.2,134.7,132.1$, $128.8,127.3,121.4,120.1,118.9,118.7,116.2$. Anal. calcd for: $\mathrm{C}_{14} \mathrm{H}_{10} \mathrm{ClN}_{3} \mathrm{O}: \mathrm{C}, 61.89 ; \mathrm{H} 3.71$; $\mathrm{N}, 15.47$. Found: $\mathrm{C}, 61.97 ; \mathrm{H}, 3.60 ; \mathrm{N}, 15.51 \%$. HRMS $(\mathrm{m} / \mathrm{z})[\mathrm{M}-\mathrm{H}]^{-}$calcd 270.0434 , found 270.0547 .

4-[1-(3,5-dichlorophenyl)-1H-1,2,3-triazol-4-yl]-phenol 6e. Yield 54\%; mp 241-244 ${ }^{\circ} \mathrm{C} ; v_{\max }$ $(\mathrm{KBr}) / \mathrm{cm}^{-1} 3126,1614,1591,1471,1226,1177,1057,841,662 ;{ }^{1} \mathrm{H}$ NMR $\delta_{\mathrm{H}}(400 \mathrm{MHz}$, DMSO) $9.72(1 \mathrm{H}, \mathrm{s}, \mathrm{OH}), 9.24(1 \mathrm{H}, \mathrm{s}, \mathrm{CH}), 8.08(2 \mathrm{H}, \mathrm{d}, J 1.8 \mathrm{~Hz}, \mathrm{Ar}-\mathrm{H}), 7.76(1 \mathrm{H}, \mathrm{t}, J$ $1.8 \mathrm{~Hz}, \mathrm{Ar}-\mathrm{H}), 7.73(2 \mathrm{H}, \mathrm{d}, J 8.7 \mathrm{~Hz}, \mathrm{Ar}-\mathrm{H}), 6.89(2 \mathrm{H}, \mathrm{d}, J 8.7 \mathrm{~Hz}, \mathrm{Ar}-\mathrm{H}) ;{ }^{13} \mathrm{C}$ NMR $\delta_{\mathrm{C}}$ (101 MHz, DMSO) 158.3, 148.4, 138.8, 135.7, 128.3, 127.3, 121.2, 118.9, 116.3. Anal. calcd for: $\mathrm{C}_{14} \mathrm{H}_{9} \mathrm{Cl}_{2} \mathrm{~N}_{3} \mathrm{O}: \mathrm{C}, 54.92 ; \mathrm{H} 2.96 ; \mathrm{N}, 13.73$. Found: $\mathrm{C}, 54.85 ; \mathrm{H}, 2.91 ; \mathrm{N}, 13.86 \%$. HRMS $(m / z)$ $[\mathrm{M}-\mathrm{H}]^{-}$calcd 304.0044 , found 304.0156.

\subsection{X-ray Diffraction Measurement}

Single crystal X-ray diffraction data of the compounds 6a-e were collected at 120(2) K on a Stoe IPDS-2T diffractometer with graphite-monochromated Mo-K $\alpha$ radiation. Crystals were cooled using a Cryostream 800 open flow nitrogen cryostat (Oxford Cryosystems, Long Hanborough, Oxford, UK). Data collection and image processing were performed with X-Area 1.75 (STOE and Cie Gmbh, Darmstadt, Germany) [9]. Intensity data were scaled with LANA (part of X-Area) in order to minimize differences of intensities of symmetry-equivalent reflections (multi-scan method). Structures were solved by direct methods, and all non-hydrogen atoms were refined with anisotropic displacement parameters by a full-matrix least squares procedure based on F2 using the SHELX-2014 program package [10,11]. The Olex [12] and Wingx [13] suites were used to prepare the final version of the CIF files. Mercury [14] was used to prepare the figures and to calculate the planes of six-membered rings. Hydrogen atoms were refined using an isotropic model with $\mathrm{Uiso}(\mathrm{H})$ values fixed to be 1.2 times $\mathrm{U}_{\text {eq }}$ for $-\mathrm{CH}$ groups. The hydrogens of $\mathrm{OH}$ groups were refined freely. A summary of crystallographic data is shown in Table 3.

Table 3. Crystal data and structure refinement for $6 \mathbf{a}-\mathbf{e}$.

\begin{tabular}{|c|c|c|c|c|c|}
\hline Identification Code & $6 a$ & $6 b$ & $6 c$ & $6 d$ & $6 e$ \\
\hline Empirical formula & $\mathrm{C}_{14} \mathrm{H}_{10} \mathrm{FN}_{3} \mathrm{O}$ & $\mathrm{C}_{14} \mathrm{H}_{9} \mathrm{~F}_{2} \mathrm{~N}_{3} \mathrm{O}$ & $\mathrm{C}_{14} \mathrm{H}_{8} \mathrm{~F}_{3} \mathrm{~N}_{3} \mathrm{O}$ & $\mathrm{C}_{14} \mathrm{H}_{10} \mathrm{ClN}_{3} \mathrm{O}$ & $\mathrm{C}_{14} \mathrm{H}_{9} \mathrm{Cl}_{2} \mathrm{~N}_{3} \mathrm{O}$ \\
\hline Formula weight (u) & 255.25 & 273.24 & 291.23 & 271.70 & 306.14 \\
\hline Temperature (K) & $120(2)$ & $120(2)$ & $120(2)$ & $120(2)$ & $120(2) \mathrm{K}$ \\
\hline Wavelength $(\AA)$ & 0.71073 & 0.71073 & 0.71073 & 0.71073 & 0.71073 L \\
\hline Crystal system & Triclinic & Monoclinic & Monoclinic & Monoclinic & Monoclinic \\
\hline Space group & $P-1$ & $P 2_{1} / n$ & $P 2_{1} / c$ & $P 2_{1} / c$ & $P 2_{1} / c$ \\
\hline \multicolumn{6}{|l|}{ Unit cell dimensions } \\
\hline a $(\AA)$ & $7.138(4)$ & $8.2384(16)$ & $9.162(3)$ & $27.8104(14)$ & $13.590(8)$ \\
\hline $\mathrm{b}(\AA)$ & $11.869(4)$ & $11.772(2)$ & $10.218(4)$ & $5.6525(2)$ & $14.898(6)$ \\
\hline c $(\AA)$ & $14.148(4)$ & $12.358(3)$ & $12.658(4)$ & $7.3445(4)$ & $14.307(8)$ \\
\hline$\alpha\left(^{\circ}\right)$ & $89.54(2)$ & 90 & 90 & 90 & 90 \\
\hline$\beta\left(^{\circ}\right)$ & $75.50(3)$ & $102.211(17)$ & $93.66(3)$ & $94.728(4)$ & $116.70(4)$ \\
\hline$\gamma\left({ }^{\circ}\right)$ & $88.42(3)$ & 90 & 90 & 90 & 90 \\
\hline Volume $\left(\AA^{3}\right)$ & $1160.0(8)$ & $1171.4(4)$ & $1182.5(7)$ & 1150.61(9) & $2588(3)$ \\
\hline $\mathrm{Z}$ & 4 & 4 & 4 & 4 & 8 \\
\hline$Z^{\prime}$ & 2 & 1 & 1 & 1 & 2 \\
\hline
\end{tabular}


Table 3. Cont.

\begin{tabular}{|c|c|c|c|c|c|}
\hline Identification Code & $6 a$ & $6 b$ & $6 c$ & $6 d$ & $6 e$ \\
\hline $\begin{array}{l}\text { Density (calculated) } \\
\left(\mathrm{Mg} / \mathrm{m}^{3}\right)\end{array}$ & 1.462 & 1.549 & 1.636 & 1.568 & 1.571 \\
\hline $\begin{array}{l}\text { Absorption coefficient } \\
\left(\mathrm{mm}^{-1}\right)\end{array}$ & 0.107 & 0.123 & 0.139 & 0.326 & 0.499 \\
\hline $\mathrm{F}(000)$ & 528 & 560 & 592 & 560 & 1248 \\
\hline Crystal size (mm) & $\begin{array}{c}0.154 \times 0.116 \times \\
0.064\end{array}$ & $\begin{array}{c}0.47 \times 0.24 \times \\
0.105\end{array}$ & $\begin{array}{c}0.646 \times 0.383 \times \\
0.238\end{array}$ & $\begin{array}{c}0.31 \times 0.174 \times \\
0.092\end{array}$ & $\begin{array}{c}0.269 \times 0.209 \times \\
0.151\end{array}$ \\
\hline $\begin{array}{l}\text { Theta range for data } \\
\text { collection }\left(^{\circ}\right)\end{array}$ & 2.270 to 25.995 . & 2.416 to 25.997. & 2.564 to 25.986 & 2.204 to 25.997 & 2.099 to 26.000 \\
\hline Index ranges & $\begin{aligned}-8 & \leq \mathrm{h} \leq 8 \\
-14 & \leq \mathrm{k} \leq 14 \\
-17 & \leq 1 \leq 17\end{aligned}$ & $\begin{array}{l}-9 \leq \mathrm{h} \leq 10 \\
-14 \leq \mathrm{k} \leq 14 \\
-15 \leq 1 \leq 15\end{array}$ & $\begin{array}{l}-10 \leq \mathrm{h} \leq 11 \\
-12 \leq \mathrm{k} \leq 12 \\
-15 \leq 1 \leq 15\end{array}$ & $\begin{array}{c}-34 \leq \mathrm{h} \leq 34 \\
-6 \leq \mathrm{k} \leq 5 \\
-8 \leq 1 \leq 9\end{array}$ & $\begin{array}{l}-16 \leq \mathrm{h} \leq 16 \\
-18 \leq \mathrm{k} \leq 18 \\
-17 \leq 1 \leq 17\end{array}$ \\
\hline Reflections collected & $1 \overline{2}, 53 \overline{8}$ & $1 \overline{4}, 02 \overline{5}$ & $1 \overline{4}, 45 \overline{5}$ & 5871 & $1 \overline{6}, 62 \overline{7}$ \\
\hline Independent reflections & $\begin{array}{c}4556 \\
{[\mathrm{R}(\mathrm{int})=0.0543]}\end{array}$ & $\begin{array}{c}2297 \\
{[R(\text { int })=0.0282]}\end{array}$ & $\begin{array}{c}2325 \\
{[\mathrm{R}(\mathrm{int})=0.0268]}\end{array}$ & $\begin{array}{c}2223 \\
{[R(\text { int })=0.0330]}\end{array}$ & $\begin{array}{c}5074 \\
{[R(\text { int })=0.0311]}\end{array}$ \\
\hline $\begin{array}{c}\text { Completeness to theta }= \\
25.242^{\circ}\end{array}$ & $99.9 \%$ & $100.0 \%$ & $99.9 \%$ & $98.6 \%$ & $99.7 \%$ \\
\hline Refinement method & $\begin{array}{c}\text { Full-matrix } \\
\text { least-squares on } \\
\mathrm{F}^{2}\end{array}$ & $\begin{array}{c}\text { Full-matrix } \\
\text { least-squares on } \\
\mathrm{F}^{2}\end{array}$ & $\begin{array}{c}\text { Full-matrix } \\
\text { least-squares on } \\
\mathrm{F}^{2}\end{array}$ & $\begin{array}{c}\text { Full-matrix } \\
\text { least-squares on } \\
\mathrm{F}^{2}\end{array}$ & $\begin{array}{c}\text { Full-matrix } \\
\text { least-squares on } \\
\mathrm{F}^{2}\end{array}$ \\
\hline Data/restraints/parameters & $4556 / 0 / 352$ & $2297 / 0 / 185$ & $2325 / 0 / 194$ & $2223 / 0 / 176$ & $5074 / 0 / 369$ \\
\hline Goodness-of-fit on $\mathrm{F}^{2}$ & 1.050 & 1.054 & 1.063 & 1.111 & 1.058 \\
\hline $\begin{array}{l}\text { Final R indices (I > } \\
\text { 2sigma(I)) }\end{array}$ & $\begin{aligned} \mathrm{R} 1= & 0.0708, \mathrm{wR} 2 \\
& =0.1924\end{aligned}$ & $\begin{aligned} \mathrm{R} 1= & 0.0303, \mathrm{wR} 2 \\
& =0.0830\end{aligned}$ & $\begin{aligned} \mathrm{R} 1= & 0.0315, \mathrm{wR} 2 \\
& =0.0825\end{aligned}$ & $\begin{aligned} \mathrm{R} 1= & 0.0369, \mathrm{wR} 2 \\
& =0.0869\end{aligned}$ & $\begin{aligned} \mathrm{R} 1= & 0.0409, \mathrm{wR} 2 \\
& =0.1051\end{aligned}$ \\
\hline $\mathrm{R}$ indices (all data) & $\begin{aligned} \mathrm{R} 1= & 0.0975, \mathrm{wR} 2 \\
= & 0.2167\end{aligned}$ & $\begin{aligned} \mathrm{R} 1= & 0.0339, \mathrm{wR} 2 \\
= & 0.0848\end{aligned}$ & $\begin{aligned} \mathrm{R} 1= & 0.0379, \mathrm{wR} 2 \\
= & 0.0858\end{aligned}$ & $\begin{aligned} \mathrm{R} 1= & 0.0513, \mathrm{wR} 2 \\
= & 0.0948\end{aligned}$ & $\begin{aligned} \mathrm{R} 1= & 0.0543, \mathrm{wR} 2 \\
& =0.1121\end{aligned}$ \\
\hline Extinction coefficient & $0.064(10)$ & $\mathrm{n} / \mathrm{a}$ & $\mathrm{n} / \mathrm{a}$ & $\mathrm{n} / \mathrm{a}$ & $\mathrm{n} / \mathrm{a}$ \\
\hline $\begin{array}{l}\text { Largest diff. peak and hole } \\
\left(\mathrm{e} \cdot \AA^{-3}\right)\end{array}$ & 0.384 and -0.318 & 0.266 and -0.202 & 0.239 and -0.195 & 0.299 and -0.378 & 0.308 and -0.386 \\
\hline CCDC number & $2,063,930$ & $2,063,931$ & $2,063,934$ & $2,063,932$ & $2,063,933$ \\
\hline
\end{tabular}

CCDC 2,063,930-2,063,934 contain the supplementary crystallographic data for this paper. These data can be obtained free of charge from The Cambridge Crystallographic Data Centre.

The Hirshfeld surfaces and 2D fingerprint plots were generated using Crystal Explorer 17.5. Crystal structures were imported from CIF files. Hirshfeld surfaces were received using a high surface resolution and mapped with the $\mathrm{d}_{\text {norm }}$ function.

\subsection{Computational Studies}

\subsubsection{The Lipinski's Rule of Five Calculations}

Calculation of the standard properties of compound 6a-e based on Lipinski's Rule of Five was performed using the SwissADME server (Swiss Institute of Bioinformatics, Lausanne, Switzerland).

\subsubsection{Ligands Preparation for Molecular Docking}

The 3D structure of ligands $6 \mathbf{a}-\mathbf{e}$, their sulfated analogs, and reference compounds (androstenedione, E1S, E1, and E2) were prepared with the Portable HyperChem 8.0.7 Release (Hypercube, Inc., Gainesville, FL, USA). Prior to docking calculations, the structure of each ligand was optimized using an $\mathrm{MM}+$ force field and the Polak-Ribière conjugate gradient algorithm (terminating at a gradient of $0.05 \mathrm{kcal} \mathrm{mol}^{-1} \AA^{-1}$ ).

\subsubsection{Protein Preparation for Molecular Docking}

The X-ray structures of the AROM, STS, 17 $\beta$-HSD1, ER $\alpha$ and ER $\beta$ used for molecular modeling studies were taken from the Protein Databank (Protein Data Bank accession codes: 3EQM, 1P49, 6MNC, 1A52, and 5TOA, respectively). After standard preparation 
procedures (including removal of water molecules and other ligands as well as addition hydrogen atoms and Gasteiger charges to each atom), docking analysis was carried out.

\subsubsection{Molecular Docking}

Docking studies were carried out using Autodock Vina 1.1.2 software (The Molecular Graphic Laboratory, The Scripps Research Institute, La Jolla, CA, USA) [15]. For the docking studies, the corresponding grid box parameters were used:

- AROM: a grid box size of $24 \AA \times 24 \AA \times 24 \AA$ centered on Asp309 amino acid residue $(\mathrm{x}=88.230, \mathrm{y}=49.522, \mathrm{z}=51.205)$;

- STS: a grid box size of $24 \AA \times 24 \AA \times 24 \AA$ centered on the fGly75 amino acid residue $(\mathrm{x}=72.135, \mathrm{y}=-1.720, \mathrm{z}=28.464)$;

- 17ß-HSD1: a grid box size of $24 \AA \times 24 \AA \times 24 \AA$ centered on Ser142 amino acid residue $(\mathrm{x}=20.760, \mathrm{y}=-6.625, \mathrm{z}=-22.837)$;

- ER $\alpha$ : a grid box size of $24 \AA \times 24 \AA \times 24 \AA$ centered on Glu353 $(x=105.702, y=$ 19.417, $\mathrm{z}=103.747)$;

- ERß: a grid box size of $24 \AA \times 24 \AA \times 24 \AA$ centered on Met336 $(x=16.635, y=$ $41.368, \mathrm{z}=18.491$ ).

Graphic visualizations of the 3D model were generated using VMD 1.9 software (University of Illinois at Urbana-Champaign, Urbana, IL, USA). Identification of the ligand-protein interactions was performed using Discovery Studio Visualiser v20. 1. 0. 19,295 (BIOVIA, Dassault Systémes, San Diego, CA, USA).

\section{Conclusions}

In summary, we synthesized five 4-(1-phenyl-1H-1,2,3-triazol-4-yl)phenol derivatives containing halogen atoms, 6a-e. Single crystals of such compounds were obtained, and their crystal structures were successfully confirmed. The determined crystal structures were used to calculate the Hirshfeld surfaces for each of the synthesized compounds, which indicated that the structures of all compounds are mainly characterized by $\mathrm{H} \cdots \mathrm{H}$, $\mathrm{C} \cdots \mathrm{H}$, and $\mathrm{X} \cdots \mathrm{H}$ (where $\mathrm{X}$ is $\mathrm{F}$ or $\mathrm{Cl}$ ) interactions. The decomposed fingerprint plots confirmed that with the increase in the number of halogen atoms in the molecules, the interactions involving fluorine or chlorine atoms become very important or even prevail the intermolecular structure-building factor. Furthermore, the performed docking studies proved potentially effective binding of compounds based on a 4-(1-phenyl-1H-1,2,3-triazol4 -yl)phenol core to the active sites of several molecular targets (AROM, STS, 17 $\beta$-HSD1, $\mathrm{ER} \alpha$, and $\mathrm{ER} \beta$ ). Importantly, we also noticed that the halogen atoms of compounds $6 \mathbf{a}-\mathbf{e}$ play an important role in the putative binding process, and their presence is crucial for the creation of stabilizing interactions in the active sites of examined molecular targets. This finding corresponds well with the crystallographic data and Hirshfeld surfaces analysis, which indicated that the interactions involving halogen atoms are a very important structure-building factor.

Our research indicated that the studied compounds might be a great starting point in the development of inhibitors of enzymes involved in the hormone biosynthesis and signaling pathways. Importantly, the calculated binding free energies for sulfates of compounds $6 \mathbf{a}-\mathbf{e}$ were better than the binding free energy of the STS native substrate (E1S). As we mentioned, we previously reported that sulfamoylated derivatives of halogenated 4-(1phenyl-1H-1,2,3-triazol-4-yl)phenols are potent STS inhibitors, which proves our present findings. It is also worth noting that the binding free energies for compounds $6 \mathbf{a}-\mathbf{e}$ were comparable to the binding free energy of $17 \beta-H S D 1$ native substrate (E1), indicating that such compounds may also potentially demonstrate $17 \beta-H S D 1$ inhibitory properties. However, such hypothesis needs to be evaluated in further biological experiments. Additionally, our docking studies and calculations of standard PC properties indicated that compounds 6a-e demonstrate favorable drug-like features and may be potentially used as drugs. However, due to the limited accuracy of the utilized AutoDock Vina, further computational 
studies using more accurate methods (e.g., free energy perturbation calculations) should be performed for finally designed compounds.

Supplementary Materials: The following are available online. Figure S1: Molecular structure of 6b. Thermal ellipsoids at 50\%, Figure S2: Molecular structures of 6 e. Thermal ellipsoids at $50 \%$, Figure S3: Crystal packings and intermolecular interactions in 6b., Figure S4: Crystal packings and intermolecular interactions in 6c., Figure S5: Crystal packings and intermolecular interactions in 6e, Table S1: Bond lengths and angles for 6a-e, Table S2: Structural parameters for intramolecular interactions in 6a-e, Table S3: The ligand-protein (AROM) interactions (and distances [ $\AA$ ] $)$ identified using BIOVIA, Dassault Systémes, Discovery Studio Visualiser, Table S4: The ligand-protein (STS) interactions (and distances [̊̊]) identified using BIOVIA, Dassault Systémes, Discovery Studio Visualiser, Table S5: The ligand-protein (17 $\beta$-HSD1) interactions (and distances $[\AA ̊])$ identified using BIOVIA, Dassault Systémes, Discovery Studio Visualiser, Table S6: The ligand-protein (ER $\alpha$ ) interactions (and distances [Å]) identified using BIOVIA, Dassault Systémes, Discovery Studio Visualiser, Table S7: The ligand-protein (ER $\beta$ ) interactions (and distances [ $[\AA]$ ) identified using BIOVIA, Dassault Systémes, Discovery Studio Visualiser.

Author Contributions: Conceptualization, methodology, writing-original draft preparation, funding acquisition, M.D.; investigation, M.D., A.D., M.S., K.B., O.C., S.D.; writing-review and editing, M.D., A.D., K.B., O.C., S.D., supervision, J.R. All authors have read and agreed to the published version of the manuscript.

Funding: This research was funded by the National Centre for Research and Development (Poland), the TANGO program, grant agreement number TANGO-IV-A/0004/2019-00.

Institutional Review Board Statement: Not applicable.

Informed Consent Statement: Not applicable.

Data Availability Statement: Not applicable.

Conflicts of Interest: The authors declare no conflict of interest.

Sample Availability: Samples of the compounds 6a-e are available from the authors.

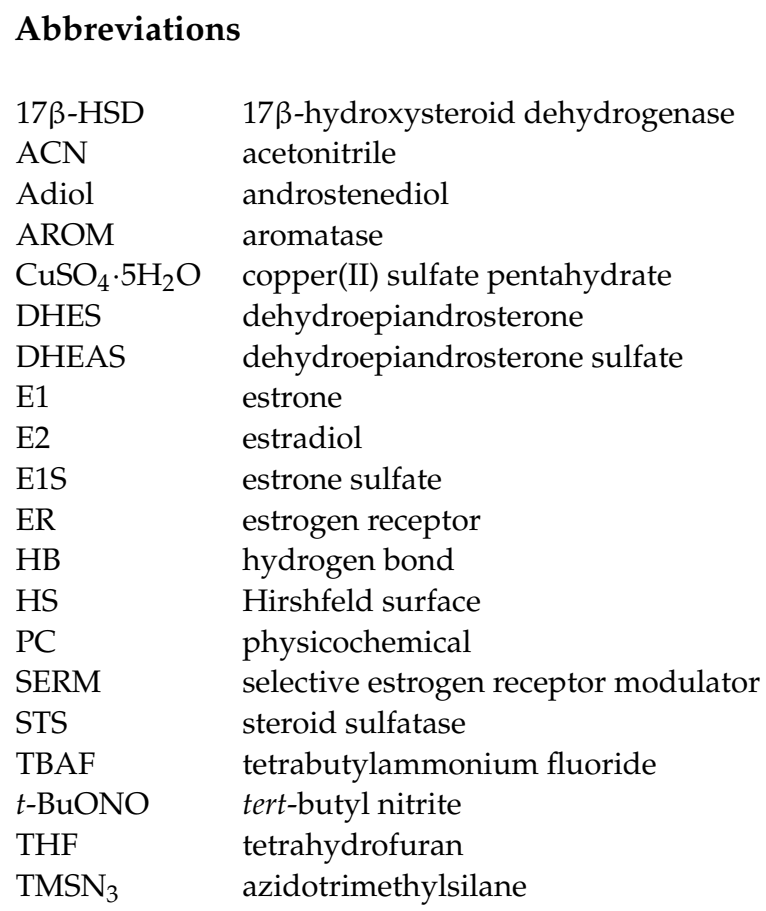

\section{References}

1. Bonandi, E.; Christodoulou, M.S.; Fumagalli, G.; Perdicchia, D.; Rastelli, G.; Passarella, D. The 1,2,3-triazole ring as a bioisostere in medicinal chemistry. Drug Discov. Today 2017, 22, 1572-1581. [CrossRef] [PubMed] 
2. Saha, T.; Makar, S.; Swetha, R.; Gutti, G.; Singh, S.K. Estrogen signaling: An emanating therapeutic target for breast cancer treatment. Eur. J. Med. Chem. 2019, 177, 116-143. [CrossRef] [PubMed]

3. Shah, R.; Singh, J.; Singh, D.; Singh Jaggi, A.; Singh, N. Sulfatase inhibitors for recidivist breast cancer treatment: A chemical review. Eur. J. Med. Chem. 2016, 114, 170-190. [CrossRef] [PubMed]

4. Muller, J.W.; Gilligan, L.C.; Idkowial, J.; Arlt, W.; Foster, P.A. The regulation of steroid action by sulfation and desulfation. Endocr. Rev. 2015, 36, 526-563. [CrossRef] [PubMed]

5. Daśko, M.; Demkowicz, S.; Rachon, J.; Biernacki, K.; Aszyk, J.; Kozak, W.; Masłyk, M.; Kubiński, K. New potent STS inhibitors based on fluorinated 4-(1-phenyl-1H-[1,2,3]triazol-4-yl)-phenyl sulfamates. J. Asian Nat. Prod. Res. 2019, 22, 1037-1044. [CrossRef] [PubMed]

6. Ciupak, O.; Daśko, M.; Biernacki, K.; Rachon, J.; Masłyk, M.; Kubiński, K.; Martyna, A.; Demkowicz, S. New potent steroid sulphatase inhibitors based on 6-(1-phenyl-1H-1,2,3-triazol-4-yl)naphthalen-2-yl sulphamate derivatives. Enzym. Inhib. Med. Chem. 2021, 36, 238-247. [CrossRef] [PubMed]

7. Sonogashira, K. Development of Pd-Cu catalyzed cross-coupling of terminal acetylenes with sp2-carbon halides. J. Organomet. Chem. 2002, 653, 46-49. [CrossRef]

8. Lipinski, C.A. Lead- and drug-like compounds. The rule-of-five revolution. Drug Discov. Today Technol. $2004,1,337-341$. [CrossRef] [PubMed]

9. X-Area 1.75, Software Package for Collecting Single-Crystal Data on STOE Area-Detector Diffractometers, for Image Processing, Scaling Reflection Intensities and for Outlier Rejection; STOE and Cie GmbH: Darmstadt, Germany, 2015.

10. Sheldrick, G.M. Crystal structure refinement with SHELXL. Acta Crystallogr. Sect. C Struct. Chem. 2015, 71, 3-8. [CrossRef] [PubMed]

11. Sheldrick, G.M. SHELXL-2014; University of Göttingen and Bruker AXS: Karlsruhe, Germany, 2014.

12. Dolomanov, O.V.; Bourhis, L.J.; Gildea, R.J.; Howard, J.A.K.; Puschmann, H. OLEX2: A complete structure solution, refirement and analysis program. J. Appl. Cryst. 2009, 42, 339-341. [CrossRef]

13. Farrugia, L.J. WinGX and ORTEP for Windows: An update. J. Appl. Cryst. 2012, 45, 849-854. [CrossRef]

14. Macrae, C.F.; Edgington, P.R.; McCabe, P.; Pidcock, E.; Shields, G.P.; Taylor, R.; Towler, M.; van de Streek, J. Mercury: Visualization and analysis of crystal structures. J. Appl. Cryst. 2006, 39, 453-457. [CrossRef]

15. Trott, O.; Olson, A.J. AutoDock Vina: Improving the speed and accuracy of docking with a new scoring function, efficient optimization, and multithreading. J. Comput. Chem. 2010, 31, 455-461. [CrossRef] [PubMed] 